\title{
Uso de Álcool, Tabaco e Drogas por Estudantes da Área de Saúde de uma Universidade de Curitiba
}

\author{
Alcohol, Tobacco and other Drugs used by Students of \\ Health Services from a University in Curitiba \\ Nilse Chiapetti* \& Carlos Augusto Serbena \\ Universidade Tuiuti do Paraná, Curitiba, Brasil
}

\begin{abstract}
Resumo
Este estudo teve por objetivo investigar o uso de álcool, tabaco e drogas por alunos da área de saúde de uma universidade particular da cidade de Curitiba. A amostra foi composta por 538 estudantes, de 18 a 54 anos, dos Cursos de Educação Física, Fisioterapia, Nutrição e Psicologia. Empregou-se para a coleta de dados o "Questionário para o levantamento do uso de álcool, drogas e condições de saúde". Os resultados apontam para um elevado consumo de álcool e tabaco, principalmente nos Cursos de Educação Física e Psicologia, que também se destacam no consumo de outras substâncias. Observa-se um consumo mais elevado de anabolizantes pelos alunos de Educação Física, e de anfetaminas no Curso de Nutrição e Fisioterapia. Quanto à história de consumo, amigos ou conhecidos são apontados para a introdução no uso e como companhia freqüente para o consumo; como motivo de uso pela primeira vez destacam-se a busca de diversão ou prazer, e como motivos para manter o consumo, a quebra da rotina, para curtir os efeitos e para reduzir a ansiedade/estresse. Cerca de $30 \%$ dos alunos consumiram uma ou mais substâncias anteriormente à universidade.
\end{abstract}

Palavras-chave: Uso de drogas; estudantes universitários; fatores de risco.

\begin{abstract}
The aim of this research was to investigate the consumption of alcohol, tobacco and other drugs by students of health services from a private university in Curitiba, the state capital of Paraná, Brazil. The sample was composed of 538 students between 18 and 54 years old, taking major degrees in Physical Education, Physiotherapy, Nutrition and Psychology. An anonymous self-completed questionnaire has been used to collect socio-demographic data and to identify patterns of non-medical use of psychoactive drugs, as well as getting information about the history of use of these substances. The results have shown an elevated consumption of alcohol and tobacco, mostly from Physical Education and Psychology majors, which have also stood out as consumers of others substances. An elevated consumption of anabolic steroids by the students of Physical Education and a high consumption of amphetamines in Nutrition and Physiotherapy majors was detected. Concerning the history of consumption, friends and acquaintances have been pointed out as the main inductors for these kinds of substances and as regular company when consuming the drugs, recreation and pleasure have been highlighted as the motives for using the drugs for the first time, and breaking up routines, to enjoy the effects and to reduce anxiety/stress are highlighted as motives to maintain consumption. Around $30 \%$ of the students have used one or more substances before attending university.

Keywords: Drug use; university students; risks factors.
\end{abstract}

O consumo de drogas (lícitas e ilícitas) transformou-se em uma preocupação mundial nas últimas décadas, em função de sua alta incidência e dos riscos à saúde derivados de seu uso (Galduróz, Noto, Nappo \& Carlini, 2003; Nicastri \& Ramos, 2001; Tavares, Béria \& Lima, 2004).

Estudos desenvolvidos em diversas partes do mundo revelam que a introdução ao consumo tem ocorrido cada vez mais precocemente e que tal uso também ocorre de forma cada vez mais pesada. No Brasil pesquisas como a que foi realizada pelo Centro Brasileiro de Informações sobre Drogas Psicoativas (CEBRID) a respeito do uso indevido de drogas por estudantes dos antigos $1^{\circ}$ e $2^{\circ}$ graus, em dez

* Endereço para correspondência: Rua Francisco Glicério, 1345 - Residencial Guarapari, apto 101 - Zona 7 - CEP 87030-050 - Maringá/PR. capitais brasileiras, reforçam esses achados (Galduróz, Noto \& Carlini, 1997). É no período da adolescência, com a vontade de tornar-se independente da família, que as drogas costumam ser experimentadas por muitos jovens. A grande maioria dos que virão a tornar-se dependentes usaram drogas pela primeira vez entre os 14 e os 18 anos (Baus, Kupek \& Pires, 2002; Kerr-Corrêa, Andrade, Bassit \& Boccuto, 1999; Ribeiro, Pergher \& Torossian, 1998; Tavares, Béria \& Lima, 2001; Zaitter, 1994).

Segundo Zaslow e Takanishi (1993), a adolescência é um período de rápido desenvolvimento e sucessão de eventos. Mudanças profundas ocorrem no corpo, na mente, nos relacionamentos e na visão de mundo, em um curto período de tempo, favorecendo uma maior exposição a fatores de 
risco, os quais podem facilitar, por exemplo, a inserção no uso de substâncias psicoativas. Kazdin (1993) acrescenta que os adolescentes não possuem ainda a habilidade para prever os riscos de um comportamento habitual, o que os torna mais vulneráveis ao envolvimento em comportamentos de risco, como o uso e abuso de substâncias, especialmente quando são mais agressivos e impulsivos.

Conforme Zaitter (1994), na maioria dos casos é possível identificar problemas emocionais, tais como relacionamento familiar abalado, conflitos internos, crise existencial e não aceitação de normas, entre os fatores de risco relacionados ao abuso destas substâncias. A curiosidade quanto aos efeitos e sensações que as drogas propiciam e o exibicionismo, visto como auto-afirmação, também são fatores de risco comuns.

A família influi diretamente, tanto como protetora quanto promotora do consumo de substâncias psicoativas pelos filhos. Conforme Chiapetti (2001) e Kazdin (1993), a estrutura e a dinâmica familiar inadequadas destacam-se, particularmente durante a pré-adolescência e adolescência, no incremento da vulnerabilidade do sujeito ao desenvolvimento de comportamentos de risco, tais como o uso de substâncias psicoativas. Quando se trata de famílias extremamente autoritárias ou liberais, há um aumento no risco de os filhos virem a consumir drogas. De forma complementar, Baus, Kupek e Pires (2002) consideram que o risco aumenta quando os pais são separados ou quando os jovens moram com outras pessoas. A adversidade e desajuste familiar e a associação com colegas delinqüentes, na adolescência, são fortes indicadores para o aparecimento do abuso de substâncias psicoativas. Além disso, adolescentes de pais consumidores pesados ou dependentes de substâncias psicoativas tendem a adotar o mesmo comportamento. O envolvimento dos filhos no consumo de substâncias dos pais (buscar uma taça para colocar vinho, trazer uma caixa de fósforos para acender o cigarro ou comprar um maço de cigarros no bar) também é considerado fator de risco proporcionado pela família.

Por outro lado, adolescentes cujos pais oferecem diretrizes claras, e ao mesmo tempo encorajam seus filhos a assumirem certos riscos e exercerem sua liberdade, levando em conta o que a idade deles comporta, de alguma maneira estão mais protegidos de comportamentos de risco, incluindo o uso de substâncias (Jessor, 1993). Famílias compostas por ambos os pais tendem a ser mais protetoras (Dougherty, 1993; Jessor, 1993; Zaslow \& Takanishi, 1993). O maior fator familiar de proteção em relação ao uso de drogas e outros comportamentos de riscos é a conexão entre os pais e os filhos. Há relação entre o afeto e o interesse dos pais, o tempo passado com seus filhos, a firmeza de medidas disciplinares assumidas e a abstenção no uso de drogas (Baus, Kupek \& Pires, 2002; Brook et al., 1998).

A comunidade também imprime proteção e riscos ao adolescente. No âmbito comunitário a escola é o ambiente de maior influência. Adolescentes que se sentem parte da comunidade escolar e contam com expectativas positivas dos pais com relação ao seu sucesso escolar estão mais protegidos contra comportamentos de risco (Jessor, 1993).
A comunidade também inclui o trabalho. Adolescentes que trabalham mais de vinte horas por semana têm mais chances de envolverem-se em comportamentos de risco, como o uso de substâncias (Jessor, 1993). Outra importante instituição comunitária, de acordo com o autor, é a religião. Adolescentes que mantêm práticas religiosas estão mais protegidos.

Zaitter (1994) considera que outro fator comunitário de ação protetora e promotora de riscos é o grupo de amigos. É do senso comum a idéia de que os filhos podem ser corrompidos pela má influência dos amigos. Conforme Zaitter, um grupo de amigos é um conjunto de indivíduos com as mesmas necessidades e desejos. $\mathrm{O}$ autor ressalta ainda que a presença dos pais na amizade dos filhos e o entendimento da natureza das aproximações feitas por eles (ao invés de simplesmente coibi-las ou entendê-las como uma fase) são fatores de proteção.

Reforçando a importância do grupo de amigos, pesquisas mostram que a experimentação inicial se dá pelo fato de o adolescente ter amigos que usam drogas, gerando uma pressão do grupo na direção do uso (Pechansky, Szobot \& Scivoletto, 2004). Kerr-Corrêa, Andrade, Bassit e Boccuto (1999), a partir de um estudo efetuado com estudantes de medicina da Universidade Estadual Paulista (UNESP), observaram que a inserção no consumo de drogas ilícitas deu-se quase sempre por meio dos amigos e colegas de faculdade.

Por fim, a mídia é um dos contextos de maior persuasão comunitária sobre o comportamento dos indivíduos. O consumo de substâncias, sobretudo de álcool e cigarros, encontra-se presente, e é frequentemente estimulado, em anúncios comerciais, filmes, letras de música e outros meios de comunicação de massa. A apresentação dessas substâncias associadas a fatores desejáveis como prazer, beleza, sucesso financeiro e sexual, poder e outros, de forma explícita ou implícita, configura-se num importante fator de risco para o seu uso (Jessor, 1993; Zaslow \& Takanishi, 1993).

No que concerne especificamente ao uso de substâncias no Brasil, pesquisas revelam que o álcool é a substância mais consumida pelos jovens, seguida pelo tabaco, maconha e estimulantes. Os solventes são populares principalmente entre os adolescentes mais novos.

Uma dessas pesquisas, realizada por Baus, Kupek e Pires (2002) entre alunos de $1^{\circ}$ e $2^{\circ}$ graus de uma escola de Florianópolis, em 2002, apontou para um aumento do risco em alunos com idade superior a 15 anos, sendo de três vezes para o uso de cocaína, mais de cinco para alucinógenos, mais de sete para a maconha e mais que o dobro para tranqüilizantes. Quanto ao sexo, as mulheres, demonstraram possuir o dobro de chance de usarem medicamentos para emagrecer ou ficar acordadas e um pouco mais que o dobro de chance de usar de tranqüilizantes. No entanto apresentaram risco duas vezes menor de uso de solventes. O índice de uso de álcool foi 10\% menor em alunos de classe $\mathrm{C}$ e $\mathrm{D}$ do que em alunos de classe $\mathrm{A}$ e $\mathrm{B}$, e o consumo de cigarro e maconha foi maior entre indivíduos que residiam com outras pessoas sem ser os pais. 
Constatou-se na pesquisa referida um elevado uso de álcool e tabaco, sendo a utilização da primeira substância maior nas classes socioeconômicas mais altas. Quanto às drogas ilícitas, verificou-se maior consumo na classe média. Percebeu-se também uma associação entre o uso de cocaína e crack, e alucinógenos e solventes, sendo o risco quase quádruplo nas classes socioeconômicas mais baixas (Baus, Kupek \& Pires, 2002).

Corroborando esses dados, em uma investigação realizada na cidade de Cuiabá entre estudantes do Ensino Fundamental e Médio da rede pública, Souza e Martins (1998) verificaram que a primeira substância de consumo entre as drogas arroladas em seu estudo foi o álcool, e a segunda, o tabaco. Da mesma forma, Kerr-Corrêa, Andrade, Bassit e Boccuto (1999) observaram um índice de uso de álcool elevado entre os alunos de Medicina da UNESP, ainda que o índice de uso de outras drogas tenha se revelado menor do que o observado em outras populações com a mesma idade, gênero e nível socioeconômico. Andrade et al. (1997), também baseados em pesquisa realizada com estudantes de medicina da Universidade de São Paulo, evidenciaram que há maior índice de uso destas substâncias nos últimos anos do curso, especialmente de tranqüilizantes, e que na maioria das vezes este uso é experimental e esporádico.

Bortoletto (1990) aponta o alcoolismo como problema social e ressalta que sua gravidade pode ser verificada por meio das estatísticas de criminalidade, violência no trânsito, absenteísmo e acidentes de trabalho, eventos freqüentemente associados ao consumo de álcool. Este ponto de vista é corroborado por Souza e Martins (1998), que lembram que o alcoolismo é a mais freqüente das toxicomanias em todo o mundo e que é reconhecido como doença pela Organização Mundial de Saúde.

Tais considerações evidenciam a necessidade e importância de programas de prevenção ao uso e abuso de drogas. A partir de um estudo que buscou levantar fatores associados ao consumo de álcool e drogas entre estudantes da área de ciências biológicas de uma universidade pública da cidade de São Paulo, Silva, Malbergier, Stempliuk e Andrade (2006) sugerem entre as estratégias úteis para a prevenção do uso de drogas nessa população: educação com treino de habilidades para a busca de melhores maneiras de lidar com o estresse, detecção precoce do uso de substâncias, fornecimento de informação científica e programas de professores e/ou tutores treinados para detectar problemas dessa natureza.

Deve-se ressaltar que a implantação de programas de prevenção ao uso de álcool, tabaco e drogas, demanda o conhecimento da realidade do consumo, incluindo aspectos relacionados ao consumo geral e em populações específicas, bem como no que diz respeito aos tipos de drogas consumidos, e ainda indicadores estatísticos sobre as suas conseqüências (hospitalares, mortes, apreensões, entre outras) (Canoletti \& Soares, 2004; Galduróz, Noto, Nappo \& Carlini, 2003).

A pesquisa da qual se deriva esse relato teve por objetivo investigar o consumo de álcool, cigarros e drogas por estudantes de cursos da área de saúde de uma universidade particular da cidade de Curitiba, bem como tipos de substâncias consumidos e fatores relacionados à historia de consumo.

\section{Método}

A pesquisa foi realizada com 538 estudantes, situados na faixa etária de 18 a 54 anos, de ambos os sexos, de todos os turnos, da área de Ciências Biológicas e de Saúde de uma universidade particular da cidade de Curitiba. Destes, 128 eram alunos dos Cursos de Educação Física (23,8\%), 106 do Curso de Fisioterapia (19,7\%), 41 do Curso de Nutrição $(7,6 \%)$ e 263 do Curso de Psicologia (48,9\%). Atualmente está sendo realizada uma investigação sobre o consumo de substâncias nos demais cursos da área de Saúde da mesma universidade (Biologia, Enfermagem, Farmácia Bioquímica, Medicina Veterinária e Odontologia), no âmbito de um programa de tratamento e prevenção ao uso e abuso de substâncias criado recentemente na instituição.

Para a coleta de dados foi empregado um questionário de autopreenchimento proposto pela Organização Mundial da Saúde, denominado "Questionário para o levantamento do uso de álcool, drogas e condições de saúde”, também utilizado por Kerr-Corrêa et al. (2001). O instrumento contém 161 questões de múltipla escolha, a maior parte das quais visando levantar informações sobre o uso na vida, nos últimos 12 meses e nos últimos 30 dias, das seguintes substâncias: álcool, tabaco, maconha, alucinógenos, cocaína, anfetaminas, anticolinérgicos, solventes orgânicos, tranqüilizantes, ansiolíticos, opiáceos, sedativos e barbitúricos. Uma parte do questionário está direcionada à obtenção de informações sobre dados sociodemográficos, condições gerais de saúde, percepção do próprio desempenho acadêmico, expectativas para o futuro (profissional), atitudes frente ao uso de substâncias psicoativas, atitudes frente a pacientes alcoolistas e farmacodependentes, aspectos relacionados à história de consumo de drogas, qualidade de vida, lazer, entre outros aspectos.

Os dados foram coletados no mês de novembro de 2003. O questionário foi aplicado nas classes, com a anuência dos professores, e a aplicação teve a duração média de vinte minutos.

A análise dos dados sobre os aspectos relativos à história de consumo de substâncias e sobre a prevalência do uso de álcool, tabaco e drogas foi realizada através do total geral de respostas afirmativas encontradas em cada curso. Buscou-se analisar a significância das diferenças entre os cursos no que diz respeito ao consumo de substâncias, através do teste Qui-quadrado. Considerando um intervalo de confiança de $95 \%(p=0,05)$, para o conjunto dos cursos a margem de erro é de $3,65 \%$, sendo diferente, entretanto, para cada curso isoladamente, em razão do tamanho da amostra. A menor margem é a relativa ao Curso de Psicologia (5\%), seguido pelo de Educação Física (7\%), Fisioterapia (8\%) e, por último, Nutrição (13\%).

Para complementar a apreciação dos dados obtidos foi realizada também uma análise da relação entre curso e padrão de uso, através da tabela de contingência, utilizando o método proposto por Pereira (2001), que inclui a avaliação do resíduo padronizado por meio do teste do Qui-quadrado, e a suposição da distribuição normal para cada padrão de uso considerado. Nesta análise o ponto de corte foi $\mathrm{z}=1,7$ (indicando $p=0,089$ ). 


\section{Resultados}

A idade média dos participantes, situados na faixa etária de 17 a 54 anos, é de 24,4 anos $(D P=7,33)$ e aproximadamente metade tem até 22 anos. Como já foi apontado, $48,9 \%$ dos sujeitos são alunos do Curso de Psicologia, 23,8\% do Curso de Educação Física, 19,7\% do Curso de Fisioterapia e 7,6\%, do Curso de Nutrição. Estudam principalmente no turno da manhã $(42,8 \%)$ e noite $(43,8 \%)$, restando uma pequena parcela que estuda à tarde $(13,5 \%)$. A maioria $(73,4 \%)$ dos participantes é do sexo feminino. Quanto ao estado civil, os participantes são, em sua maioria, solteiros (76,7\%); 19,2\% são casados ou vivem com companheiro(a) e 3,9\% são separados.

No que se refere aos aspectos relacionados à história de uso de drogas ou álcool pelos estudantes (exceto cigarros), foram objeto de análise a introdução no uso de substâncias (incluindo álcool), o motivo de uso na primeira vez, a companhia freqüente para o uso, os motivos indicados para uso freqüente e o uso de drogas anterior à universidade.

A introdução no consumo de álcool ou drogas, entre os participantes que fazem ou já fizeram uso, deu-se principalmente através de "colegas, amigos ou conhecidos", o que se aplica a 22,2\% dos estudantes de Educação Física, 13,8\% dos alunos de Fisioterapia, 7,7\% dos de Nutrição e 22,1\% dos de Psicologia. Uma pequena parcela deles, que representa 7,9\% dos alunos de Educação Física, 3\% dos de Fisioterapia, 10,3\% dos de Nutrição e 8,4\% dos de Psicologia relatam que começaram a utilizar drogas ou álcool por "outros meios", que não sob influência de colegas, amigos ou conhecidos, namorados(a) e companheiros(a) e/ ou da família. Uma parcela ainda menos expressiva, que atinge $3 \%$, no máximo, indica "namorado(a) e companheiro(a)", a "família”, ou dois ou mais dos tipos de influência considerados.

Quanto ao motivo de uso na primeira vez, $13,6 \%$ dos alunos de Curso de Educação Física, o que representa a maioria dos alunos desse curso que fazem ou fizeram uso, informam que começaram a usar em busca de "diversão ou prazer"; o segundo motivo mais indicado pelos alunos desse curso foi a "curiosidade", com 8\%. O uso de substâncias pela primeira vez para "melhorar o desempenho" (no estudo, sexual ou social) foi indicado por $6,4 \%$ dos participantes. O principal motivo para o início do uso no Curso de Psicologia, aponta- do por $18,7 \%$, foi a "curiosidade"; $14,1 \%$ dos alunos indicam a busca de "diversão ou prazer" como motivo. Entre os alunos do Curso de Fisioterapia, o principal motivo indicado foi a "curiosidade", por 11,8\% dos alunos, seguido pela busca de "diversão ou prazer", por 7,8\% dos alunos. No Curso de Nutrição, os motivos mais indicados foram a busca de "diversão ou prazer" e a "curiosidade", com 7,5\% dos alunos, em ambas. Um percentual pouco expressivo dos alunos dos cursos considerados indicam a busca de "alívio de tensão ou outros sintomas", e "uso por amigos ou namorado(a)", como motivos para o uso pela primeira vez.

No que se refere à companhia freqüente para uso de drogas, a maioria dos alunos que fazem ou já fizeram uso de drogas indicam que isso ocorre ou ocorreu em companhia de "amigos e colegas": 29,3\% dos alunos de Educação Física, 15,3\% dos de Fisioterapia, 13,2\% dos alunos de Nutrição e 24,8\% dos alunos de Psicologia indicam esse tipo de companhia. O uso "sozinho" é assinalado por $5,7 \%$ dos alunos de Educação Física, $2 \%$ dos de Fisioterapia e 1,2\% dos de Psicologia. 2,4\% dos estudantes de Educação Física, 3, $1 \%$ dos de Fisioterapia e 4,8\% dos de Psicologia citaram dois ou mais dos tópicos apresentados, indicando que isso pode variar.

Entre os motivos para uso freqüente de drogas, o mais referido é "para quebrar a rotina e/ou curtir os efeitos", por 16,5\% dos alunos de Educação Física, 9,2\% dos alunos de Fisioterapia, $16,2 \%$ dos alunos de Nutrição e $14,2 \%$ dos alunos de Psicologia. O segundo motivo mais referido é "para diminuir a ansiedade e estresse", sendo que para o Curso de Educação Física este foi o mais citado, com 18,2\%. Nos Cursos de Fisioterapia e Psicologia, 6,1\% e 8,1\%, respectivamente, apontam esta opção como motivo. Outro motivo, "para participar do grupo de amigos ou colegas", foi citado por 2,5\% dos alunos de Educação Física, 2\% dos de Fisioterapia e $4,9 \%$ dos de Psicologia.

No que se refere ao início do uso de substâncias, conforme a tabela $1 \mathrm{o}$ uso anterior ao ingresso na universidade ocorreu para aproximadamente um terço dos alunos dos Cursos de Educação Física e Psicologia e um quarto dos alunos dos Cursos de Nutrição e Fisioterapia. As substâncias utilizadas pelos estudantes foram principalmente maconha, solventes, anfetaminas e, em menor freqüência, alucinógenos.

Tabela 1

Uso de Substâncias anterior à Universidade

\begin{tabular}{|c|c|c|c|c|}
\hline Curso & Educação Física (\%) & Fisioterapia (\%) & Nutrição (\%) & Psicologia (\%) \\
\hline \multicolumn{5}{|l|}{ Opções } \\
\hline não & 63,9 & 75,2 & 74,4 & 67,4 \\
\hline $\operatorname{sim}$ & 36,1 & 24,8 & 25,6 & 32,6 \\
\hline Substâncias de uso anterior à universidade & & & & \\
\hline maconha & 50 & 40 & 36,4 & 47,8 \\
\hline alucinógenos & 2 & - & - & - \\
\hline cocaina e/ou crack & 6 & - & - & - \\
\hline anfetaminas & 6 & 10 & 18,2 & 3,3 \\
\hline solventes & 4 & 23,3 & - & 5,4 \\
\hline dois ou mais dos acima & 32 & 26,7 & 45,5 & 43,5 \\
\hline Sujeitos $(\mathrm{n}) *$ & 128 & 106 & 41 & 263 \\
\hline
\end{tabular}

Nota. *Esses valores são válidos para as demais tabelas, salvo indicação em contrário. 
Entre os alunos que fizeram uso de substâncias antes de entrar na universidade, a maconha foi a principal droga de uso, tendo sido indicada por metade dos alunos de Educação Física, quase metade dos de Psicologia, e por mais de um terço dos alunos de Fisioterapia e Nutrição. A segunda droga de escolha foi o solvente, sendo mais comum seu uso no Curso de Fisioterapia, por cerca de um quarto dos alunos. O uso de anfetaminas foi indicado por aproximadamente um quinto dos alunos do Curso de Nutrição, um décimo dos alunos do Curso de Fisioterapia e um percentual menor dos alunos dos Cursos de Educação Física e Psicologia. O uso de alucinógenos e de cocaína e/ou crack foi indicado apenas no Curso de Educação Física (2\% e 6\%, respectivamente). O uso de duas ou mais substâncias anteriormente ao ingresso na universidade foi indicado por quase metade dos alunos dos Cursos de Nutrição e Psicologia, cerca de um terço dos alunos de Educação Física e cerca de um quarto dos alunos de Fisioterapia.

As Tabelas 2 e 3 referem-se ao uso de álcool e tabaco e outras drogas pelos estudantes na vida, no ano e no mês de realização da pesquisa.
Conforme os dados da tabela 2 , a grande maioria dos alunos de todos os cursos indicou o uso de álcool ao longo da vida e a maioria indicou o uso no último ano; o uso no último mês foi indicado por cerca de três quartos dos alunos dos Cursos de Psicologia e Educação Física e dois terços dos alunos de Fisioterapia e Nutrição.

A indicação do consumo de tabaco ao longo da vida variou de $41,5 \%$ a $65,1 \%$, ocorrendo percentual maior nos Cursos de Psicologia e Educação Física, seguidos pelos Cursos de Nutrição e Fisioterapia. O consumo no ano destaca-se no Curso de Psicologia, com pouco mais de um terço; nos demais cursos o consumo no ano é indicado por cerca de um quarto dos alunos. O consumo diário de tabaco também é maior no Curso de Psicologia, com quase um terço do total de alunos; nos demais cursos o consumo diário de tabaco aparece com índices também relevantes, de cerca de um quinto ou pouco menos. O consumo no mês aparece com índices relevantes: quase metade dos alunos do Curso de Psicologia indicam esta ocorrência e nos demais cursos, um pouco menos ou mais de um terço do total.

Tabela 2

Prevalência de Uso de Álcool e Tabaco na Vida, nos Últimos 12 Meses e nos Últimos 30 Dias

\begin{tabular}{|c|c|c|c|c|c|c|c|c|c|c|c|c|}
\hline \multirow{3}{*}{ Curso } & \multicolumn{6}{|c|}{ Álcool (\%) - ocorrência } & \multicolumn{6}{|c|}{ Tabaco (\%)- ocorrência } \\
\hline & \multirow[t]{2}{*}{ vida } & \multirow[t]{2}{*}{ ano } & \multicolumn{4}{|c|}{ mês } & \multirow[t]{2}{*}{ vida } & \multirow[t]{2}{*}{ ano } & \multicolumn{4}{|c|}{ mês } \\
\hline & & & $\begin{array}{c}\text { menos } \\
\text { de } \\
1 \mathrm{x} / \text { sem.* }\end{array}$ & $\begin{array}{c}1 \mathrm{ou} \\
\text { mais } \\
\mathrm{x} / \mathrm{sem} \text {. }\end{array}$ & $\begin{array}{c}\text { uso } \\
\text { diário }\end{array}$ & $\begin{array}{l}\text { Total } \\
\text { último } \\
\text { mês }\end{array}$ & & & $\begin{array}{c}\text { menos } \\
\text { de } \\
1 \mathrm{x} / \text { sem. }\end{array}$ & $\begin{array}{c}1 \text { ou } \\
\text { mais } \\
\mathrm{x} / \text { sem. }\end{array}$ & $\begin{array}{c}\text { uso } \\
\text { diário }\end{array}$ & $\begin{array}{l}\text { Total } \\
\text { último } \\
\text { mês }\end{array}$ \\
\hline Ed. Física & 93,6 & 55,9 & 38,6 & 31,5 & 4,7 & 74,8 & 59 & 22 & 12,7 & 7,1 & 19,1 & 38,9 \\
\hline Fisioterapia & 93,3 & 65,4 & 39,2 & 26,5 & 4,9 & 70,6 & 53,8 & 25 & 11,9 & 9,9 & 14,9 & 36,7 \\
\hline Nutrição & 78,1 & 53,7 & 53,7 & 7,3 & 2,4 & 63,4 & 41,5 & 24,4 & 9,8 & 2,4 & 19,5 & 31,7 \\
\hline Psicologia & 96,7 & 67,6 & 47,9 & 24,9 & 3,8 & 76,6 & 65,1 & 37,9 & 10,4 & 3,5 & 31,6 & 45,5 \\
\hline
\end{tabular}

Notas. ${ }^{*} \mathrm{x} /$ sem. $=$ vezes por semana.

Tabela 3

Prevalência de Uso de Drogas* na Vida, nos Últimos 12 Meses e nos Últimos 30 Dias

\begin{tabular}{l|c|c|c|c|c|c|c|c|c|c|c|c}
\hline \multicolumn{1}{c|}{ Curso } & \multicolumn{3}{c|}{ Educação Física } & \multicolumn{3}{c|}{ Fisioterapia } & \multicolumn{3}{c|}{ Nutrição } & \multicolumn{3}{c}{ Psicologia } \\
\hline \multicolumn{1}{c|}{ ocorrência } & vida & ano & mês & vida & ano & mês & vida & ano & mês & vida & ano & mês \\
\hline Substância & & & & & & & & & & & & \\
\hline maconha (\%) & 38,6 & 21,3 & 25,2 & 23,2 & 8,7 & 9,7 & 26,9 & 9,8 & 7,3 & 43,1 & 15,3 & 16,7 \\
alucinógenos (\%) & 19,6 & 3,1 & 3,9 & 5,8 & 0 & 2 & 7,3 & 2,4 & 0 & 10 & 0,8 & 3,2 \\
cocaína (\%) & 15,8 & 1,6 & 1,6 & 6,7 & 1,9 & 3 & 4,8 & 2,4 & 0 & 11,8 & 3,4 & 5 \\
anfetaminas (\%) & 20,4 & 9,4 & 14,9 & 11,5 & 3,8 & 7 & 29,2 & 14,6 & 9,7 & 24 & 3,4 & 7,8 \\
ecstasy (\%) & 8,7 & 2,4 & 3,2 & 1,9 & 1,9 & 0 & 4,8 & 2,4 & 0 & 2,6 & 1,1 & 2 \\
solventes & & & & & & & & & & & \\
orgânicos (\%) & 26,7 & 3,9 & 5,5 & 21,2 & 4,8 & 7,9 & 14,7 & 4,9 & 2,4 & 26,8 & 4,6 & 13,6 \\
opiáceos (\%) & 9,4 & 4,7 & 4,8 & 8,6 & 1,9 & 1 & 9,7 & 2,4 & 2,4 & 10,7 & 1,1 & 6,7 \\
sedativos ou & & & & & & & & & & \\
barbitúricos (\%) & 6,3 & 0 & 3,1 & 2 & 1 & 1 & 4,9 & 0 & 4,8 & 5,3 & 1,1 & 4,3 \\
anabolizantes (\%) & 12,6 & 4,7 & 7,9 & 2,9 & 1 & 2 & 0 & 0 & 0 & 1,5 & 0,4 & 1,6 \\
\hline
\end{tabular}

Nota. *São consideradas as substâncias mais indicadas pelos estudantes, exceto álcool e tabaco. 
No que se refere ao consumo de outras substâncias, os dados da tabela 3 apontam para um consumo mais elevado de maconha, solventes e anfetaminas, considerando-se a amostra total. A análise das diferenças entre os valores representativos da prevalência de consumo das diversas substâncias consideradas pelos alunos dos diferentes cursos, através do teste de proporções, supondo distribuição normal, indica diferenças significantes $(p<0,05)$ nos padrões de consumo de algumas substâncias, sobretudo no que diz respeito ao uso de maconha, alucinógenos, anfetaminas, ecstasy e anabolizantes, conforme é apontado nos parágrafos a seguir. Não houve sensibilidade do teste para o Curso de Nutrição, devido ao reduzido tamanho da amostra $(n=41)$, não sendo possível estabelecer conclusões estatisticamente significativas relativas ao mesmo. Ainda assim os percentuais observados permitem algumas indicações.

A maconha é destacada como a principal droga de uso em todos os cursos, variando de 43,1\%, no Curso de Psicologia, a 23,2\%, no Curso de Fisioterapia, na opção uso ao longo da vida. O uso durante o ano e no último mês foi indicado por um quarto e um quinto dos alunos de Educação Física, respectivamente, aproximadamente um sexto dos de Psicologia e cerca de um décimo dos de Nutrição e Fisioterapia. A análise aponta para diferença significante $(\mathrm{p}<0,05)$ no padrão de uso de maconha entre os Cursos de Educação Física e Fisioterapia quanto ao uso na vida, ano e mês, Educação Física e Psicologia quanto ao uso na vida, e Fisioterapia e Psicologia quanto ao uso na vida. Destacam-se os índices mais elevados de uso de maconha nos Cursos de Psicologia e Educação Física, em relação aos outros cursos, em todos os níveis de freqüência analisados, sobretudo na opção uso na vida.

No que se refere ao uso de alucinógenos, assinalaram a utilização ao longo da vida cerca de um quinto dos acadêmicos de Educação Física, um décimo dos de Psicologia e um percentual pouco menor dos de Nutrição e Fisioterapia. $\mathrm{O}$ uso no último ano é indicado pelos alunos do Curso de Educação Física, principalmente, com percentual em torno de $3 \%$. O uso no último mês é indicado nos Cursos de Educação Física e Psicologia, por cerca de 3,5\%. É interessante assinalar que os alunos do Curso de Fisioterapia indicaram uso apenas no último mês (2\%) e os de Nutrição no último ano $(2,4 \%)$ (além do uso na vida). A análise aponta para diferença com nível de significância $(p<0,05)$ entre Educação Física e Fisioterapia, e entre Educação Física e Psicologia, quanto ao uso na vida, com maior consumo pelos alunos de Educação Física.

Em relação ao uso de cocaína, é importante notar que mais uma vez os Cursos de Psicologia e Educação Física apresentam consumo sensivelmente mais elevado do que nos outros cursos, sobretudo no que se refere ao consumo na vida, uma vez que cerca de um em cada sete a oito alunos desses cursos informam que já fizeram uso dessa substância. O consumo no ano e no mês é baixo, ganhando expressividade um pouco maior no Curso de Educação Física.

O uso de anfetaminas na opção ao longo da vida foi apontado por pouco menos de um terço dos alunos de Nutrição, um quarto dos de Psicologia, um quinto dos de Educação
Física e um em cada nove dos alunos de Fisioterapia. O uso ao longo do ano e/ou no último mês é destacado nos Cursos de Nutrição e Educação Física, com percentuais variando de $9,5 \%$ a $15 \%$. Já os Cursos de Psicologia e Fisioterapia apresentam um índice maior de consumo no último mês, em torno de $7 \%$, do que ao longo do ano, em torno de 3,5\%.

Há diferença estatisticamente significante $(p<0,05)$ entre os Cursos de Educação Física e Fisioterapia nos três níveis de freqüência de uso analisados, com consumo mais elevado no primeiro curso, e entre este e o Curso de Psicologia, com maior consumo na vida no Curso de Psicologia e índices sensivelmente mais baixos de consumo no ano e no último mês. Assim, existe uma indicação evidente de consumo mais elevado desta substância no Curso de Nutrição, como se pode observar na tabela 3 , mas o tamanho reduzido da amostra $(n=41)$ não confere sensibilidade ao teste para este curso, como já foi mencionado.

Em relação ao ecstasy, há maior indicação de uso ao longo da vida nos Cursos de Educação Física $(8,7 \%)$ e Nutrição $(4,8 \%)$; o uso ao longo do ano é indicado por cerca de $2 \%$ dos alunos de todos os cursos e a utilização no último mês variou de $2 \%$ a $3,2 \%$ em todos os cursos pesquisados, exceto Nutrição, onde foi nula. Observa-se maior índice de alunos que referem uso, sobretudo ao longo da vida, no Curso de Educação Física, em relação aos Cursos de Fisioterapia e Psicologia, com diferença estatisticamente significante $(p<0,05)$.

Quanto à freqüência do uso de Solventes Orgânicos, o uso ao longo da vida foi indicado por pouco mais de um quarto dos alunos de Educação Física e Psicologia, cerca de um quinto dos alunos de Fisioterapia e pouco menos de um em cada nove acadêmicos de Nutrição. $\mathrm{O}$ uso durante $\mathrm{o}$ ano variou de $3,9 \%$ a $4,8 \%$ nos cursos pesquisados. Salienta-se o alto índice de uso no último mês em Psicologia (13,6\%) se comparado aos outros cursos, nos quais o uso encontra-se entre $4,6 \%$ e $5,5 \%$ do total.

Em relação aos opiáceos percebe-se percentual ao redor de $10 \%$ de alunos que indicam ter usado ao longo da vida em quase todos os cursos e um pouco menos $(8,6 \%)$ em Fisioterapia. O uso no último mês foi assinalado principalmente nos Cursos de Psicologia (6,7\%) e Educação Física (4,8\%), sendo que nesse curso o mesmo percentual ocorre para o uso ao longo do ano. Os alunos dos Cursos de Nutrição e Fisioterapia indicaram percentuais de 1 a $2 \%$ para os usos ao longo do ano e no último mês.

Quanto ao uso de sedativos ou barbitúricos, a utilização ao longo da vida é indicada por aproximadamente um em cada vinte alunos de Educação Física, Psicologia e Nutrição. Os alunos desses cursos também apontaram o uso no último mês, mas com percentuais variando de $3,1 \%$ a $4,8 \%$. Isso contrasta com a utilização ao longo do ano, que praticamente não é indicada, chegando ao máximo de $1 \%$, aproximadamente, em todos os cursos pesquisados. O Curso de Fisioterapia teve índice de $1 \%$ a $2 \%$ em todas as opções de uso dessa substância.

Percebe-se percentuais mais expressivos de alunos que indicam consumo de anabolizantes no Curso de Educação Física: $12,6 \%$ ao longo da vida, $4,7 \%$ durante o ano e $7,9 \%$ no último mês. Esses índices contrastam com os percentuais dos 
outros cursos que variam de $0 \%$ a $2 \%$ em todas as opções, exceto no Curso de Fisioterapia no uso ao longo da vida, com $2,9 \%$. Há diferença significante $(p<0,05)$ no padrão de uso de anabolizantes entre os Cursos de Educação Física e Fisioterapia e entre este último e Psicologia, em todos os níveis de freqüência analisados: uso na vida, ano e último mês. Em suma, observa-se um consumo mais elevado de anabolizantes entre os estudantes de Educação Física.

A Tabela 4 apresenta a soma de todos os percentuais de ocorrência de consumo de drogas, excetuando maconha ou haxixe (além de álcool e tabaco), que aparece com percentuais semelhantes e elevados nos diversos cursos. Como um mesmo indivíduo pode consumir uma ou mais drogas, os percentuais podem ultrapassar a totalidade (100\%). Realizando-se esta análise para as ocorrências de uso na vida, mês e ano, obtém-se um índice que quantifica aproximadamente o consumo de drogas, em geral, por curso, permitindo comparações.

A análise do padrão de ocorrência de consumo das substâncias nos diferentes cursos, realizada pelo teste de pro- porções, supondo distribuição normal, indica diferenças significativas nas seguintes ocorrências:

1. Nos percentuais apresentados para o consumo na vida entre o Curso de Educação Física e todos os outros cursos, e entre o Curso de Psicologia e todos os outros $\operatorname{cursos}(p<0,05)$.

2. Nos percentuais apresentados para o consumo no último ano entre os Cursos de Educação Física e Fisioterapia, e entre Educação Física e Psicologia $(p<0,05)$.

3. Nos percentuais apresentados para o consumo no último mês entre os Cursos de Educação Física e Fisioterapia, Educação Física e Nutrição, e ainda entre Psicologia e Educação Física e Psicologia e Nutrição $(p<0,05)$.

Como se pode observar, os dados apontam para um consumo maior de substâncias, em geral, entre os estudantes dos Cursos de Educação Física e Psicologia, com destaque para Educação Física, em todos os níveis de freqüência de consumo considerados.

Tabela 4

Soma dos Percentuais de Consumo de Substâncias por Curso*

\begin{tabular}{ccccc}
\hline Ocorrências & \multicolumn{4}{c}{ Cursos } \\
& Educação & & & \\
& Física (\%) & Fisioterapia & Nutrição & Psicologia \\
\hline vida & 119,5 & 60,6 & 75,4 & 92,7 \\
ano & 29,8 & 16,3 & 29,1 & 15,9 \\
mês & 44,9 & 23,9 & 19,3 & 44,2 \\
n & 128 & 106 & 41 & 263 \\
\hline
\end{tabular}

Nota. *Alucinógenos, cocaína, anfetaminas, ecstasy, solventes orgânicos, opiáceos, sedativos ou barbitúricos e anabolizantes.

A análise da relação entre curso e padrão de uso através da tabela de contingência mostrou-se adequada apenas para maconha e bebida alcoólica, pois a tabela relativa ao consumo das demais substâncias apresenta $25 \%$ das células com contagem menor que 5 . Ainda assim, e com estas ressalvas, foi mantido este modo de análise também para as demais substâncias, pois ele destaca os padrões de uso que podem se diferenciar significativamente entre os cursos e permite levantar hipóteses.

Foram encontradas diferenças significativas no padrão de uso de bebida alcoólica, tabaco, maconha, alucinógenos, anfetaminas, ecstasy e anabolizantes.

Em relação a tabaco, observa-se uma diferença significativa entre os cursos $\left(\lambda^{2}=27,06 ; d f=12 ; p=0,008\right)$ destacando-se a não utilização entre os alunos do Curso de Nutrição $(z=1,8 ; p=0,072)$ e a utilização no último ano no Curso de Psicologia $(z=2,2 ; p=0,028)$.

Constata-se uma diferença significativa $\left(\lambda^{2}=26,61 ; d f=9\right.$; $p=0,002)$ no padrão de uso de bebida alcoólica entre os cursos. A diferença provavelmente se deva ao fato de que a freqüência de alunos do Curso de Psicologia que nunca utilizaram bebida alcoólica $(z=-1,8 ; p=0,072)$ é inferior à dos outros cursos.
No padrão de uso de maconha ou haxixe há diferença significativa entre os cursos $\left(\lambda^{2}=23,47 ; d f=9 ; p=0,005\right)$. A diferença encontra-se principalmente na baixa utilização no último ano pelos alunos do Curso de Fisioterapia ( $z=-1,7 ; p=0,089)$, contrastando com a alta utilização pelos alunos do Curso de Educação Física ( $z=+1,8 ; p=0,072)$, em comparação com os alunos dos demais cursos, e pela maior freqüência de alunos do Curso de Psicologia que experimentaram essa substância alguma vez $(z=1,7 ; p=0,089)$, em comparação com os demais.

No padrão de uso de alucinógenos há diferença significativa entre os cursos $\left(\lambda^{2}=17,391 ; d f=9 ; p=0,043\right)$. A diferença encontra-se principalmente na utilização alguma vez na vida $(z=1,8 ; p=0,072)$, que não no último ano $(z=1,7$; $p=0,089)$, e também no último ano $(z=1,8 ; p=0,072)$, pelos alunos de Educação Física .

Em anfetaminas observam-se as seguintes diferenças $\left(\lambda^{2}=24,416 ; d f=9 ; p=0,003\right)$ : os alunos de Psicologia contrastam o alto índice de uso na opção alguma vez na vida $(z=1,9 ; p=0,057)$ com a baixa utilização dos alunos de Fisioterapia ( $z=-2,0 ; p=0,046)$, entretanto essa tendência não se mantém para os alunos de Psicologia no último ano, onde 
se observa uma baixa freqüência de consumo $(z=-1,6$; $p=0,11)$. Na forma de utilização no último ano, destacam-se os alunos de Educação Física ( $z=1,7 ; p=0,089)$, e particularmente os de Nutrição $(z=2,3 ; p=0,021)$.

Quanto ao uso de ecstasy, o teste indicou diferença $\left(\lambda^{2}=\right.$ $12,458 ; d f=6 ; p=0,05)$, destacando-se a utilização na opção alguma vez na vida pelos alunos de Educação Física ( $z=2,8$; $p=0,005)$.

Finalmente, relativamente ao uso de anabolizantes foi constatada diferença importante entre os $\operatorname{cursos}\left(\lambda^{2}=28,667\right.$; $d f=6 ; p=0,000)$, destacando-se o alto uso entre alunos de Educação Física nos padrões de consumo na vida ( $z=3,4$; $p=0,001)$ e no último ano $(\boldsymbol{z}=3,0 ; p=0,003)$.

\section{Discussão}

Em se tratando de aspectos relacionados à história de uso de drogas ou álcool pelos estudantes, constata-se que a introdução no uso se deu através de "colegas, amigos ou conhecidos", sendo estes também indicados como companhia freqüente para o uso de drogas. O motivo do uso pela primeira vez foi fundamentalmente a busca de "diversão ou prazer", ou ainda "curiosidade". Esses resultados são muito semelhantes àqueles apontados por Kerr-Corrêa, Andrade, Bassit e Boccuto (1999), que realizaram uma pesquisa dessa natureza com estudantes do Curso de Medicina da UNESP.

Os motivos mencionados para o uso freqüente de drogas ou álcool são principalmente a "quebra de rotina" e "para curtir efeitos destas substâncias", seguidos pela "diminuição da ansiedade ou estresse". Estes motivos foram igualmente predominantes em pesquisa similar realizada por Kerr-Corrêa et al. (2001), também com alunos da UNESP.

$\mathrm{O}$ uso de substâncias (exceto cigarros e álcool) anterior à universidade atinge um percentual próximo de $30 \%$, considerando-se todos os cursos, com índices mais elevados de alunos que informam ter consumido alguma substância nos Cursos de Educação Física (36,1\%) e Psicologia (32,6\%). De modo semelhante, Barría, Queiroz, Nicastri e Andrade (2000) e Kerr-Corrêa et al. (2001) concluíram, a partir de pesquisas com alunos da Universidade de São Paulo (USP) e da UNESP, respectivamente, que muitos dos universitários que experimentaram alguma droga o fizeram antes de entrar na universidade.

As substâncias mais consumidas isoladamente antes do ingresso na universidade, conforme os resultados, foram a maconha, em todos os cursos, com percentuais mais elevados nos Curso de Educação Física e Psicologia (50\% e 47,8\%, respectivamente), os solventes, no Curso de Fisioterapia (23,3\%), e as anfetaminas no Curso de Nutrição (18,2\%). É elevada a proporção dos que indicam ter consumido mais de um tipo de substância. Com base nos resultados de sua pesquisa, Kerr-Corrêa et al. (2001) apontam que as drogas mais utilizadas pelos estudantes da UNESP antes do período universitário eram a maconha $(14,6 \%)$ e os solventes $(5,4 \%)$.

Os resultados anunciados acima corroboram a posição de autores como Baus, Kupek e Pires (2002), Kerr-Corrêa et al. (1999), Ribeiro, Pergher e Torossian (1998) Tavares, Béria e Lima (2001) Zaitter (1994), entre outros, que asseveram que a introdução no consumo de substâncias tem ocorrido cada vez mais precocemente e de forma cada vez mais comprometedora. Conforme complementam Kazdin (1993) e Zaslow e Takanishi (1996) as drogas freqüentemente são experimentadas na adolescência, período marcado por intensas modificações de natureza biopsicossocial, e por isso mesmo caracterizado por uma maior vulnerabilidade à adoção de comportamentos de risco, como o uso e abuso de substâncias.

No que se refere ao uso de substâncias ao longo da vida, no último ano e no último mês, o álcool é a droga mais utilizada pelos alunos da universidade pesquisada: considerando-se todos os cursos, uma média de 90,5\% informam ter experimentado na vida, $60,7 \%$ informam que fizeram uso nos últimos doze meses e $71,4 \%$ no último mês. O consumo no último mês é mais elevado nos Cursos de Psicologia (76,6\%) e no de Educação Física $(74,8 \%)$. Embora o uso na vida tenha sido indicado por quase todos os alunos, o uso diário atinge a média de 4\%. Conforme relatam Andrade et al. $(1995,1997)$ e Kerr-Corrêa et al. (2001), o álcool também foi apontado como a substância mais utilizada por estudantes da UNESP e da USP, com percentuais de consumo próximos àqueles encontrados na presente pesquisa.

O uso diário de tabaco é indicado por uma maior proporção dos alunos do Curso de Psicologia (31,6\%), sendo menos significativo nos outros cursos $(17,8 \%$, em média, considerando-se os outros três cursos). Este foi utilizado por mais da metade dos alunos no que se refere ao padrão de uso "na vida" ( $55 \%$, considerando-se uma média de todos os cursos), com percentuais mais elevados nos Cursos de Psicologia e Educação Física (65,1\% e 59\%, respectivamente).

Considerando-se as médias encontradas em todos os cursos no consumo de tabaco, 27,3\% dos alunos indicam uso durante o ano, $38,2 \%$ no último mês e $21,3 \%$ diariamente, com um percentual mais elevado no Curso de Psicologia, em todos os padrões de consumo considerados: $37,9 \%$ no último ano, $45,5 \%$ no último mês, seguindo a tendência observada quanto ao uso diário $(31,6 \%)$, conforme já foi apontado. Também é expressivo o percentual de alunos do Curso de Educação Física e Fisioterapia que indicam uso no último mês (38,9\% e $36,7 \%$, respectivamente). Nota-se que os alunos do Curso de Medicina da UNESP (Kerr-Corrêa et al., 1999) mostraram um índice mais baixo de uso: $33 \%$ utilizaram tabaco durante a vida, $7 \%$ no mês e $2 \%$ diariamente.

A utilização de drogas ao longo da vida, englobando todas as substâncias psicoativas investigadas no questionário, com exceção de álcool e tabaco, foi indicada por 11,35\% dos alunos pesquisados (média de todos os cursos), sendo que as mais usadas foram maconha, solventes e anfetaminas. Em pesquisas realizadas com estudantes universitários do estado de São Paulo, tanto por Andrade et al. (1995, 1997), quanto por KerrCorrêa et al. (2001), o índice de alunos que consumiram algum tipo de substância, na vida, foi muito próximo do aqui indicado, e as substâncias mais utilizadas foram as mesmas.

Exceto pela maconha, que é a substância ilícita mais utilizada em todos os cursos, pode-se perceber a droga de uso predominante e a incidência de consumo de substâncias, de 
modo geral, difere nos vários cursos. No Curso de Psicologia destaca-se o uso do cigarro, especialmente no último mês $(45,5 \%)$, e de maconha, solventes e anfetaminas, sobretudo ao longo da vida $(43,1 \%, 26,8 \%$ e $24 \%$, respectivamente). No Curso de Educação Física observa-se uma freqüência também elevada de uso de cigarro, maconha e anfetaminas, sobretudo no último mês $(38,9 \%, 25,2 \%$ e $14,9 \%$, respectivamente), e de alucinógenos e anabolizantes, principalmente no padrão de "uso na vida" (19,6\% e 12,6\%, respectivamente). Por outro lado, há um evidente consumo mais expressivo de anfetaminas pelos alunos do Curso de Nutrição ao longo da vida (29,2\%). É de se destacar, além disso, o fato de que os Cursos de Psicologia e Educação Física apresentam índices mais elevados de consumo, alternando-se na primeira posição na maior parte das substâncias consideradas.

Tais especificidades e variações na incidência de consumo de substâncias nos diferentes cursos permitem o levantamento de algumas hipóteses. A incidência mais elevada de consumo da maior parte das substâncias consideradas, nos Cursos de Psicologia e Educação Física, principalmente de tabaco e maconha, talvez esteja relacionada a uma abertura maior à experimentação de alterações nos estados subjetivos, ligadas ao uso de substâncias psicoativas, bem como à "curiosidade" e busca de "diversão ou prazer", principais motivos apontados para a introdução no uso de drogas pelos estudantes.

A partir dos resultados de uma pesquisa que buscou investigar o comportamento do universitário da área de Ciências Biológicas da Universidade de São Paulo, em relação ao uso de drogas, Barría, Queiroz, Nicastri e Andrade (2000) referem que os fumantes de seu estudo aparentemente eram mais sedentários, preocupando-se pouco com a saúde, uma vez que praticavam menos esportes, assim como mantinham o hábito de fumar. Ainda que no presente estudo não tenham sido apreciados dados relativos à prática esportiva, comprometendo um análise adequada, poder-se-ia supor uma provável relação dessa natureza, principalmente em relação aos alunos de Psicologia, principais fumantes. Entretanto essa hipótese parece menos aplicável aos estudantes de Educação Física, uma vez que se trata de um curso no qual atividades esportivas são supostamente um componente essencial e presente.

Barría, Queiroz, Nicastri e Andrade (2000), a partir dos resultados de sua pesquisa, também observaram uma relação entre uma maior freqüência a eventos culturais, como festas e outros, e a presença do hábito de fumar, sugerindo que a aquisição do hábito de fumar ocorra pelo fato dos fumantes estarem mais expostos e ligados a outros fumantes quando vão a festas ou outros eventos, podendo o cigarro ser considerado, nesse caso, como um meio de aproximação entre as pessoas.

A maior prevalência de uso de anabolizantes pelos alunos de Educação Física, por sua vez, possivelmente esteja associada à busca de "melhora no desempenho" (nos estudos, sexual e/ou social), um dos motivos citados para o uso freqüente de drogas nesse curso. Segundo Lise, Silva,
Ferigolo e Barros (1999), os esteróides anabolizantes androgênicos (EAA) são drogas que aumentam a massa muscular, a força física e a agressividade em competições, além de diminuir o tempo de recuperação entre exercícios intensos, o que talvez explique, parcialmente, o consumo mais elevado entre os alunos desse curso. Manetta e Silveira (2000) ressaltam, além disso, que os anabolizantes vêm sendo utilizados de maneira abusiva por atletas profissionais e também por atletas recreativos.

O Curso de Nutrição destaca-se no uso de anfetaminas ao longo da vida, seguido pelo de Psicologia, também quanto ao uso na vida, e Educação Física, no último mês. É de se notar que no Curso de Nutrição há um percentual mais elevado (apesar das ressalvas devidas ao tamanho reduzido da amostra) de alunos que apontam o uso desse tipo de substância antes do ingresso na universidade. Conforme refere o CEBRID (2003) essa substância tem sido freqüentemente utilizada em fórmulas de emagrecimento, especialmente nas últimas décadas, permitindo levantar a hipótese de que houvesse, entre estudantes desse curso, antes mesmo do ingresso na universidade, um esforço para a redução do peso corporal e/ou manutenção do peso dentro dos limites desejáveis.

É importante lembrar, além disso, que Nutrição e Psicologia são cursos cujos alunos são predominantemente do sexo feminino, que normalmente sofre maior pressão social para a manutenção de um corpo magro. Quanto aos alunos do Curso de Educação Física, sobretudo as mulheres, é possível que sofram uma pressão ainda maior nesse sentido, explicando a elevada incidência de consumo de anfetaminas no último mês, nesse curso. Entretanto é necessário considerar que algumas formas de anfetamina também são muito utilizadas pelo seu efeito estimulante sobre a atividade do sistema nervoso central, deixando os usuários mais "acesos", "ligados”, reduzindo o sono (CEBRID, 2003), o que também poderia explicar, em parte, o consumo mais elevado nesse curso.

Estas diferenças são importantes, pois indicam a necessidade de se considerar especificidades nos indivíduos que experimentam ou usam drogas. A esse respeito Minayo e Deslandes (1998) chamam a atenção para a complexidade existente nas relações entre o consumo de drogas, álcool e suas conseqüências, e as variáveis ecológicas, tais como o ambiente e a cultura onde os sujeitos estão inseridos.

Ressalta-se, contudo, que as considerações apresentadas acima são inferências baseadas em índices destacáveis de consumo de certas substâncias observados em determinados cursos, e inspiradas em proposições da literatura a respeito de possíveis motivações que subjazem ao consumo de cigarros, anfetaminas, anabolizantes, em particular, e de drogas, de um modo geral. Análises mais apropriadas das prováveis relações aqui inferidas demandariam novas investigações.

É importante ressaltar ainda que foram distribuídos em torno de 740 questionários, entretanto cerca de 200 não foram respondidos de forma completa. Portanto retornaram de forma válida 538 questionários (72,3\% do total). Poderiam 
existir motivos, como o receio de revelar aspectos comprometedores, para os informantes não responderem adequadamente, indicando um viés não abordado.

A partir das considerações apresentadas salienta-se a necessidade de novas pesquisas para identificar melhor as especificidades e os diferentes fatores envolvidos no consumo de substâncias, no sentido de aperfeiçoar os programas de prevenção e intervenção.

\section{Conclusões}

Relativamente a aspectos que marcam a história de uso de substâncias ou álcool pelos estudantes, pode-se verificar que:

1. A introdução no uso se deu sobretudo através de colegas, amigos ou conhecidos.

2. O motivo do uso na primeira vez foi principalmente a busca de “diversão ou prazer”. No Curso de Educação Física destaca-se também a busca de "melhora no desempenho", o que pode estar relacionado ao elevado índice de consumo de anabolizantes por alunos desse curso.

3. A exemplo do que ocorre quanto à introdução no uso, os “amigos ou colegas” são citados como companhia freqüente para o uso de drogas.

4. Os motivos mencionados para o uso freqüente de drogas são principalmente a "quebra de rotina" e "para curtir efeitos das substâncias", seguida pela "redução da ansiedade ou estresse".

5. $\mathrm{O}$ uso de substâncias anterior à universidade atinge uma média próxima de 30\%, com índice mais elevado no Curso de Educação Física (36,\%), seguido pelo de Psicologia (32,6\%). As substâncias mais consumidas foram a maconha, o que se aplica a todos os cursos, os solventes no Curso de Fisioterapia e as anfetaminas no Curso de Nutrição. Entre os estudantes que consumiram substâncias antes do ingresso na universidade, é elevada a proporção dos que indicam ter consumido mais do que um tipo, em especial nos Cursos de Nutrição (45,5\%) e Psicologia (43,5\%).

No que se refere ao álcool e tabaco, nota-se um consumo elevado, sobretudo quando se consideram os índices do último mês, para todos os cursos analisados, evidenciando-se algumas diferenças, com maior consumo no Curso de Psicologia, seguido pelo de Educação Física.

Quanto às demais substâncias (exceto álcool e tabaco), os Cursos de Psicologia e Educação Física apresentam índices mais elevados (alternando-se na primeira posição na maior parte das substâncias). O consumo de anabolizantes é sensivelmente mais elevado no Curso de Educação Física, em todas as ocorrências consideradas (uso na vida, no ano e no mês), e o de anfetaminas é significativamente superior entre os alunos do Curso de Nutrição, quando se considera o uso na vida, ainda que o consumo dessa substância no último mês seja mais elevado no Curso de Educação Física.

O consumo observado, tanto no que diz respeito a álcool e tabaco quanto a drogas ilícitas, apresenta-se em níveis próximos àqueles descritos em estudos realizados com estudantes de outras universidades e inclusive de outros estados.

Frente aos resultados obtidos na presente pesquisa, e sendo o consumo de substâncias psicoativas (lícitas e ilícitas) um problema social e de saúde pública, percebe-se a importância da realização de programas de prevenção e intervenção nessa área.

Uma parcela da população especialmente suscetível a esse problema, como já foi referido, são os jovens. Poder-seia supor, de modo genérico, que há uma homogeneidade nesse grupo quanto à realidade de consumo, o que apontaria para estratégias de prevenção e intervenção também homogêneas. Entretanto, como mostram os resultados dessa e de outras pesquisas da mesma natureza realizadas com a população jovem, em especial com estudantes universitários, existem especificidades no consumo, que se referem à quantidade, tipo de droga consumida, entre outros fatores, os quais apontam para a complexidade da relação entre o consumo dessas substâncias e o meio onde o usuário se insere. Tal complexidade aponta para a necessidade de se considerar estes fatores em programas de intervenção e prevenção ao uso e abuso de substâncias.

\section{Referências}

Andrade, A. G., Bassit, A. Z., Kerr-Corrêa, F., Tonhon, A. A., Boscovitz, E. P., Cabral, M., Rassi, R., Potério, G. M., Marcondes, E., Oliveira, M. P. M. T., Duailibi, K., \& Fukushima, J. T. (1995). Fatores de risco associados ao uso de álcool e drogas na vida, entre estudantes de medicina do Estado de São Paulo. Revista ABP-APAL, 17, 41-46.

Andrade, A. G., Queiróz, S., Villaboim, R. C. M., Cesar, C. L. G., Alves, C. G. P., Bassit, A. Z., Gentil, V., Siqueira, A. A. F., \& Tolosa, E. M. C. (1997). Uso de álcool e drogas entre alunos de graduação da Universidade de São Paulo. Revista ABP-APAL, 19(2), 53-59.

Barría, A. C. R., Queiroz, S., Nicastri, S., \& Andrade, A. G. (2000). Comportamento do universitário da área de biológicas da Universidade de São Paulo, em relação ao uso de drogas. Revista Psiquiatria Clinica, 27(4), 215-224.

Baus, J., Kupek, E., \& Pires, M. (2002). Prevalência e fatores de risco relacionados ao uso de drogas entre escolares. Revista de Saúde Pública, 36(1), 40-46.

Bortoletto, M. E. (1990). Tóxicos, civilização e saúde: Contribuição à análise dos sistemas de informações tóxico-farmacológicas no Brasil. Rio de Janeiro, RJ: Editora da Fundação Oswaldo Cruz.

Brook, J. S., Brook, D. W., De La Rosa, M., Duque, L. F., Rodríguez, E., Montoya, I. D., \& Whiteman, M. (1998). Pathways to marijuana use among adolescents: Cultural/ecological, family, peer, and personality influences. Journal of American Academy of Child $\Theta^{\circ}$ Adolescent Psychiatry, 37, 759-766.

Canoletti, B., \& Soares, C.B. (2004). Drug consumption prevention programs in Brazil: Analysis of the scientific production from 1991 to 2001, Interface (Botucatu), 9(16), 115-129.

Centro Brasileiro de Informações sobre Drogas Psicotrópicas. (2003). Livreto informativo sobre drogas psicotrópicas. São Paulo, SP: Cromosete.

Chiapetti, N. (2001). Comportamento de risco em pré-adolescentes institucionalizados. Tese de Doutorado não-publicada, Curso de Pós-graduação em Psicologia Clínica, Instituto de Psicologia, Universidade de São Paulo, SP. 
Dougherty, D. M. (1993). Adolescent health: Reflections on a repport to U.S. Congress. American Psychologist, 48(2), 193-201.

Galduróz, J. C. F., Noto, A. R., Nappo, S. A., \& Carlini, E. A. (2003). Comparações dos resultados de dois levantamentos domiciliares sobre o uso de drogas psicotrópicas no estado de São Paulo nos anos de 1999 e 2001. Jornal Brasileiro de Psiquiatria, 52(1), 43-51.

Galduróz, J. C. F., Noto, A. R., \& Carlini, E.A. (1997). Quarto levantamento sobre o uso de drogas entre estudantes de $1^{\circ}$ e $2^{\circ}$ graus em 10 capitais brasileiras - 1997. São Paulo, SP: CEBRID.

Jessor, R. (1993). Successful adolescent development among youth in high-risk settings. American Psychologist, 48(2), 117-126.

Kazdin, A. E. (1993). Adolescent mental health: Prevention and treatment programs. American Psychologist, 48(2), 127-141.

Kerr-Corrêa, F., Andrade, A. G., Bassit, A. Z., \& Boccuto, N. M. V. F. (1999). Uso de álcool e drogas por estudantes de medicina da UNESP. Revista Brasileira de Psiquiatria, 21, 95 -100.

Kerr-Corrêa, F., Dalben, I., Trinca, L. A., Simão, M. O., Mattos, P. F., Ramos-Cerqueira, A. T. A., \& Mendes, A. A. (2001). Primeiro levantamento do uso de álcool e de drogas e das condições gerais de vida dos estudantes da UNESP (1998). Série Pesquisa Vunesp, 14. São Paulo, SP: Editora da Fundação para o Vestibular da Universidade Estadual Paulista.

Lise, M. L. Z., Silva, T. S. G., Ferigolo, M., \& Barros, H. M. T. (1999). O abuso de esteróides anabólico-androgênicos em atletismo. Revista da Associação Médica Brasileira, 45(4), 364-370.

Manetta, M. C. D. P., \& Silveira, D. X. (2000). Uso abusivo de esteróides anabolizantes androgênicos. Psiquiatria na Prática Médica, 33(4). Retirado em 20 ago. 2005, de http:// www.unifesp.br/dpsiq/polbr/ppm.

Minayo, M. C. S., \& Deslandes, S. F. (1998). A complexidade das relações entre drogas, álcool e violência. Cadernos de Saúde Pública, 14(1), 35-42.

Nicastri, S., \& Ramos, S. D. P. (2001). Prevenção do uso de drogas. Revista ABEAD-JBDQ, 2(1), 25-29.
Pechansky, F., Szobot, C. M., \& Scivoletto, S. (2004). Uso de álcool entre adolescentes: Conceitos, características epidemiológicas e fatores etiopatogênicos. Revista Brasileira de Psiquiatria, 26, 14-17.

Pereira, J. C. R. (2001). Análise de dados qualitativos: Estratégias metodológicas para as ciências da saúde, humanas e sociais. São Paulo, SP: Editora da Universidade de São Paulo.

Ribeiro, T. W., Pergher, N. K., \& Torossian, S. D. (1998). Drogas e adolescência: Uma análise da ideologia presente na mídia escrita destinada ao grande público. Psicologia: Reflexão e Crítica, 1 1(3), $421-430$.

Silva, L. V. R., Malbergier, A., Stempliuk, V. A., \& Andrade, A. G. (2006). Fatores associados ao consumo de álcool e drogas entre estudantes universitários. Revista de Saúde Pública, 40(2), 280288

Souza, D. P. O., \& Martins, D. T. O. (1998). O perfil epidemiológico do uso de drogas entre estudantes de $1^{\circ}$ e $2^{\circ}$ graus da rede estadual de ensino de Cuiabá. Cadernos de Saúde Pública, 14(2), $391-400$

Tavares, B. F., Béria, J. U., \& Lima, M. S. (2001). Prevalência do uso de drogas e desempenho escolar entre adolescentes. Revista de Saúde Pública, 35(2),150-158.

Tavares, B. F., Béria, J. U., \& Lima, M. S. (2004). Fatores associados ao uso de drogas entre adolescentes escolares. Revista de Saúde Pública, 38(6), 787-796.

Zaitter, M. A. B. (1994). Drogadição: Drogas e conseqüências (3. ed.) São Paulo, SP: Lovise.

Zaslow, M. J., \& Takanishi, R. (1993). Priorities for research on adolescent development. American Psychologist, 48(2), 185-192.

Recebido: 23/11/2005 $1^{a}$ revisão: 21/09/2006

$2^{a}$ revisão: 24/11/2006 Aceite final: 04/12/2006 